\title{
Editorial
}

Digestive

\section{Mentality, Career, Mentorship: My Way}

\author{
Zsolt Tulassay \\ Internal and Gastroenterological Clinic, Semmelweis University Budapest, Budapest, Hungary
}

The consummation of the physician's individuality and the rounding out of his/her labour are dependent on a number of factors. Human characteristics, diligence, audacity, a sense of mission, and capabilities are important constituting elements. However, the development of a physician's career is not independent of outside influences. It is not only luck and material goods but also the political environment that shape a physician's career. Europe was divided into 2 parts by the post-war great power coercion until the recent decade. Those who were living in the countries of Soviet dictatorship acquired a special experience, their world view differed from that of the people who were living in luckier situation, and their value system became more nuanced and multifaceted.

We were isolated in the so-called Eastern bloc countries in the communist dictatorship from the flow of free thoughts, from the mutually beneficial exchange of experiences, from the opportunities of co-operation and travel, as well as from participation in the work of foreign scientific workshops. We had to live in a closed world, and despite the fact that the desire and commitment for the freedom of thought was living inside the majority of the people, it could not be realized in its entirety.

I was fortunate to come into contact with German gastroenterology, first and foremost owing to the support of the Humboldt Foundation, where I learnt a lot, acquired experience, and made friends. Naturally, real liberation came for us after the collapse of the Soviet dictatorship. Professor Malfertheiner initiated and organized a forum where

\section{KARGER}

() 2019 S. Karger AG, Basel

E-Mail karger@karger.com

www.karger.com/ddi members of different generations, professors and their students from all over Europe regularly met, contacts were established, co-operations and joint projects were realized; it was initially called the East-West Bridging Meeting.

However, I felt that the term "East-West" was not simply a geographic notion, but the idea of difference and isolation also haunted in it. Therefore, I suggested to Peter that our annual meeting be renamed European Bridging Meeting, as we are all Europeans, we all represent the shared European values, and friendship also connects us besides the same professional commitments. We are grateful to Professor Malfertheiner who has put this idea into practice, and who is the staunch representative and standard-bearer of the common European thought.

I would like to show you how I conceive of medical mentality career and mentorship. First of all, let me ask the question: what is career at all? Position? No! Power? No! Achieving an ambitious goal? No! Then what?

I got to learn within the bounds of dictatorship that real satisfaction and the fulfillment of a real career could be gained only from a life in which we were able to internalize truth and could represent it as well, to hold our own as best as we could at a place where destiny had put us, and to attempt not only to preserve the talents of which we can read about in the gospel, but to pass them on too. This is what real career is, and passing it on is what real mentorship is.

The most important element in the fulfillment of a career is learning to accept responsibility and to acquire the 
ability of thinking. We are physicians, and our work is dominated by medical thinking that has absolutely unique characteristics. Therefore, I believe that the climax of a physician's career is not a position; it is not acquiring power, but the idea that we should be able to become the masters of medical thinking and to pass it on.

That is how career and mentorship are related to each other.

Medical thinking was primarily shaped by studies, appropriate professional knowledge, and expertise. Thinking based on studies and expertise is made complete by the richness of experience. It is imperative to create an ability, which is able to understand the essential, and to make a distinction between the important and the unimportant. Medical thinking is characterized by perpetual scepticism that comes from the realization that information at our disposal is limited, our methods of examination are not perfect, that the same phenomenon can appear in various forms, and that our attention is not alert all the time. Scepticism takes all the bifurcations of the paths to diagnoses and helps us return to the point of departure to re-evaluate the ways covered up this point and to identify new paths forward. We should find the proper place of each element of the diagnosis mosaic. If there are different paths leading to the emergence of a phenomenon, we should find the real cause through careful research. If it is not possible then we should be aware of the fact that no real answer has been given to the question. We should be ready to assess and accept the unexpected and unusual situations.

It is the ability of deliberation that is a defining feature of a physician's thinking. We should weigh the balance between diagnosis and complication, as well as the ratio between the efforts and the results in all our decisions.

It is coupled with the ability of long-term thinking and planning. The symptoms of an unknown illness are not manifest in their entirety at first. The diagnosis is changing and progressing and can be identifiable with certainty only later on. We should know that specific pathological conditions cannot be identified with certainty in various periods of time, especially in the beginning. The experienced physician is patient, and expects the detailed exposure of the background of the symptoms from the controlling examinations.

There are a number of unknowns in the theoretical and practical healing alike. The problems of the relations between signs, connections, and the coincidence of dates, the separation of the parallel elements, the defeasibility of causal bonds, the incalculableness and variety of individual replies require that we should be prepared to taking risks. This preparedness means up-to-date scientific knowledge and solid medical scholarship, but it also presupposes a courageous and resolute mental behaviour.

The use of experiences is an essential part of thinking. We do not know the exact structure and progress of the pathological process. We cannot succeed in a lot of cases with analysis and logic because of the large number of unknown impacts. However, the preservation of experience and the "I've seen it before" mentality can assist us in such situations in finding the right way.

The exploration of the operation of the living organ has not been completed over the millennia of the history of human thinking. The question is whether the scientific cognition of the totality of life can ever be realized as a result of contemporary dramatic progress. The lack of cognition can be replaced partly by the collection of experiences and their utilization though. Healing is based on a practical system of experiences which cannot be substituted by anything else. This rule is corroborated by observations accumulated over centuries. Nevertheless, their incorporation into the individual's thinking has its limits.

The bulk of experience should be attained through individual hard work, diligence, and commitment. We should be able to enter fully situations and destinies, to analyze the connections carefully, and to formulate the results for ourselves through our own efforts, so that we could acquire the appropriate experience. Becoming a physician is a process that cannot be hastened. It is a road full of struggles, and it requires sacrifice, stamina and strong will.

We should be ready to reconsider our previous notions upon getting acquainted with new experiences, and to reevaluate the inter-relations objectively. This presupposes openness, modesty, and adaptability as well. A physician's thinking radiates loftiness which derives from a sense of mission.

Fastidiousness is one of the basic features in a physician's thinking - fastidiousness towards ourselves and our environment; the expectation of fastidiousness in thinking, in action, in work, as well as in the human and professional relations. Fastidiousness manifests itself in our efforts to do our best too. It is only a perfectly prepared homework that leads to success both in private and professional lives.

A complete success is also characterized by emotional identification. Emotional identification reinforces audacity, and helps achieve the intended goal. A job well done can extend the joy over accomplishment, and the peace of our conscience is the yardstick that can confirm that we have done our best on the road leading to the goal.

A physician is characterized by determination coupled with steadfast and strong will. Determination means that 
he or she does not accept anything else except achieving the goal.

The ability of renewal all the time is an important factor besides a value system based on traditions.

An essential part of the ability to renew is that the change could be fit into the traditional value system, and that it could adjust to the new values of a changing world by retaining its basic features. Thus, the ability to renew drawing on the traditional value system might become the source of balance and harmony.

A physician needs patience as well. Patience has many branches and it can manifest itself in various directions and relationships. We have to accept and understand the different opinions, the various approaches, and the various emotional commitments. Modesty is also an important part of patient behaviour. It is the manifestation of a virtue that makes us accept that others' views may prevail too.

This patience and modesty make it possible to prevent that unfounded satisfaction will not dominate us, and to make us possible to find our place in the community with good conscience. We should nurture personal relations with empathy. The gap between our stock of knowledge and the immensity of nexuses to be discovered demand humility. This feeling is kept alive by the difference between our knowledge and the cognition of the already established laws of the living world.

Our thinking is defined by the awareness that our work is a duty. The most important defining feature of a physician is his respect for and empathy towards the patients. His or her relations are characterized by honesty and straightforwardness, while in his or her job it is a commitment to help, self-sacrifice, and a belief in healing that define him or her.

It is also the task of a physician, besides professionalism, to help the patient keep his or her balance, faith in recovery, or at the discovery of a terminal disease to assist him keeping his mental strength and dignity. It is impossible without the influence of the physician's personality. Healing is not equal with a computer analysis of the diagnosis. Technological progress influences the physician's work, it makes it easier in various respects, but it does not alter the bases of medical thinking and the sensibility of medical behaviour. It is the single most important element, the individual and the individuality that is missing from the results of the computer analyses.

A physician should be erudite and susceptible to arts. Expertise beyond the strictly interpreted professional knowledge and the desire to get to know the environment in a broad sense are essential characteristics of the life of an intellectual.

Erudition means multifaceted and thorough knowledge. Its contents may change over time through the development of intellectual schools and technology, but its basis is still the traditional cognition turning towards humanity and the values of intellectual work.

One of the pillars of erudition is the thorough knowledge of the possibilities of language and expression. The lucid, unambiguous, and accurate speech casts light on the clarity of thoughts as well. The strength of expression, the logic of arguments, as well as the richness and beauty of vocabulary disclose the physician's personality too. Literature and arts play an important role in the rounding of the physician's individuality, as he or she can acquire a number of experiences from arts that substitute life experiences, help evaluate different situations, assist in getting to know various characters and modes of behaviour, and it also makes it possible for us to respond with empathy to trust showed to us. It is a must for an intellectual to immerse himself or herself into arts. It is extremely difficult to define what the most important characteristics are that should belong in a physician's thinking and individuality. There is not one single definition that can be termed comprehensive. However, each train of thought results in one single conclusion after all: the physician should be a good man above all else, who is enriched by knowledge, who is held in respect, and who is made a valued member of the community by patience.

A physician who offers solace to suffering people should especially represent the spirituality and erudition of humanity too.

If a physician, especially a gastroenterologist succeeds in internalizing these virtues, and he or she is thinking and acting in harmony with them, then he or she can claim to have reached the climax of human career because it is not the position, the power, and the official recognitions that make a career. Instead a career is successful if erudition, tolerance, and honesty characterize each of the physician's actions, and they radiate on his or her environment and disciples. Passing on knowledge and honesty, and showing these values are the real task of mentorship.

That is how career and mentorship meet half-way, which - as you can see - are hardly separable, and which constitute the main distinguishing elements in the real humane renaissance physician, the real teacher. 